\title{
BMJ Open Factors affecting emergency preparedness competency of public health inspectors: a cross-sectional study in northeastern China
}

\author{
Ning Ning, ${ }^{1}$ Zheng Kang, ${ }^{2}$ Mingli Jiao, ${ }^{2}$ Yanhua Hao, ${ }^{1}$ Lijun Gao, ${ }^{1}$ Hong Sun, ${ }^{3}$ \\ Qunhong $\mathrm{Wu}^{1}$
}

To cite: Ning N, Kang Z, Jiao $\mathrm{M}$, et al. Factors affecting emergency preparedness competency of public health inspectors: a cross-sectional study in northeastern China. BMJ Open 2014;4:e003832. doi:10.1136/bmjopen-2013003832

\section{- Prepublication history for this paper is available online. To view these files please visit the journal online (http://dx.doi.org/10.1136/ bmjopen-2013-003832).}

Received 16 August 2013 Revised 14 November 2013 Accepted 4 December 2013

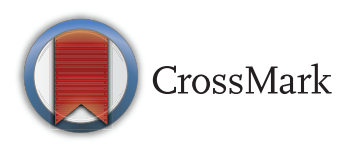

\footnotetext{
${ }^{1}$ Department of Social Medicine, School of Public Health, Harbin Medical University, Harbin, People's Republic of China ${ }^{2}$ Department of Health Policy, School of Public Health, Harbin Medical University, Harbin, People's Republic of China

${ }^{3}$ Department of Medical Demography, School of Public Health, Harbin Medical University, Harbin, People's Republic of China
}

Correspondence to Qunhong Wu; wuqunhong@163.com; and Yanhua Hao; hyhyjw@126.com

\section{ABSTRACT}

Objectives: To determine the emergency preparedness competency specific to public health inspectors (PHIs), preparedness limitations and needs of the workforce, as well as to identify important factors that affect the preparedness competency of PHIs.

Setting: Cross-sectional survey was conducted in Heilongjiang, a province in northeastern China.

Participants: A questionnaire was administered to a sample of 368 PHIs from 17 public health inspection agencies, chosen by stratified cluster sampling strategy. 9 PHIs and 6 agency's leaders were invited to participate in an in-depth interview.

Outcome measures: Self-rated preparedness competency in quantitative study was measured. Multivariate logistic regression model was used to test the associations between individual determinants and self-rated preparedness competency. Key themes relating to preparedness competency of PHIs in qualitative study were analysed.

Results: Although $82 \%$ of PHIs highly rated their general preparedness competency, there were significant differences among the assessment on specific domains of their competency. Comparing with attitude, the domains of skills and knowledge tend to be lower $(p=0.000)$. Awareness on one's own responsibilities regarding emergency response work was identified as the most important factor associated with preparedness competency (adjusted OR=6.33, $95 \% \mathrm{Cl} 3.30$ to 12.16). Lack of explicit national job requirements, overlapping responsibilities and poor collaboration among agencies, together with poor knowledge and skills level of personnel, led to an ambiguity of responsibility, and hindered the preparedness competency enhancement of PHIs furthermore.

Conclusions: Ambiguity responsibility in emergency response is still a prominent issue that hinders the further improvement on the preparedness competency for PHIs' in China. Intensified capacity-building activities targeting at individuals' weakness in specific knowledge and skills are urgently needed; in addition, capacity building at policy and system level as well as agency levels is of equal importance.

\section{Strengths and limitations of this study}

- The sample size of 368 respondents from 17 agencies in one province may limit the study power.

- The self-assessment of public health inspectors (PHIs) on preparedness competency may overestimate the actual level of their competency.

- Despite the limitations, this study provided needed evidence for future preparedness competency building for PHIs meeting the potential emergency situations at the local level.

\section{INTRODUCTION}

Public health inspectors (PHIs), also known as environmental health officers, ${ }^{1}$ are technicians committed to administering and enforcing the legislation related to public health security and protection, serving as a backbone of locally driven public health emergency response ${ }^{2} 3$ in China. Public health emergency remains threat and challenge to national and global public health security. ${ }^{4}$ Recently, the frequent outbreaks of environmental health emergencies originated from food safety, such as horsemeat scandals in Europe $^{5}$ and food safety scandals in China, ${ }^{6}$ have made PHIs become the targets of the public fury and criticism. How to assure PHIs with sufficient competencies that enable them to respond to public health threats timely and properly, which is not only the key concern of China but also key concern of the world.

The development history of PHIs in China experiences distinctive phases. ${ }^{7}$ After 1949, China, following the Soviet model, established the agency called epidemic prevention station to undertake the function of monitoring and supervising on public health in addition to disease prevention and control. The workforce, mainly majored in preventive 
medicine, paid a great attention to environmental health monitoring duties, while neglecting health law enforcement. ${ }^{7}$ With the deepening of Chinese national health system reform, ${ }^{78}$ since 2000 , epidemic prevention station has been divided into two parts: centre of disease prevention and control (CDC) and health inspection and supervision (HIS). CDC is mainly responsible for technical work of disease prevention and control, while HIS mainly deals with specialising in legal enforcement for public health, ${ }^{9}$ thus PHIs come into being an independent workforce, but a large number of PHIs are mainly from public health background; due to lack of systematic training on legal affairs and other reasons, their role and functions have not been displayed fully. ${ }^{1011}$ Especially, the recent outcry of public discontent on the performance of PHIs has pushed the Chinese government and the society to explore various factors that cause the incompetence of PHIs and disabled them from efficient response to public health threats as expected.

Being fully aware of the importance of identifying the underlying predictors for preparedness competency of PHIs, several studies have been conducted to explore its measurement in China, ${ }^{12}{ }^{13}$ but Chen's et al research showed that there was still a need to make a further improvement on the specific evaluation tool for PHIs. Based on the core emergency preparedness competencies for public health workers developed by Gebbie and Merrill $^{14}$ and the knowledge, skills and attitudes (KSAs) model developed by the Association of Schools of Public Health and CDC of America, ${ }^{15}$ this study was to explore emergency preparedness competencies specific to PHIs, determine the level of perceived competency of PHIs in China, to find out preparedness limitations and needs of the workforce as well as to identify important factors that affect the preparedness competency, providing much needed evidence for China to better preparing its PHIs to meet the challenges brought by frequent public health emergencies.

\section{METHODS}

This study was a combination of a quantitative face-to-face survey with a qualitative in-depth interview.

\section{Face-to-face survey}

The survey was carried out by researchers from Harbin Medical University in Heilongjiang province which is located in northeast China. There exist 13 jurisdictional regions and 153 agencies responsible for HIS. $^{16}$ Considering the geographical and jurisdictional diversity, stratified cluster sampling method was adopted. First, we classified 13 jurisdictional regions into three subgroups according to their regional economic development status (per capita gross domestic product, higher than $¥ 20000$, between $¥ 10000$ and $¥ 20000$ and lower than $¥ 10000$ ) according to the data from statistics yearbook of Heilongiiang province in $2011 .{ }^{17}$ In each subgroup, the other two indicators were also taken into account, which was the number of PHIs per 10000 population $(\geq 0.75$, national average level) and the coverage rate of health supervision ( $\geq 80 \%$, national average level). ${ }^{16}$ Finally, three jurisdictional regions including Harbin, Mudanjiang and Yichun were sampled. The entire 48 agencies responsible for HIS within these three regions were queried regarding interest in participating in the survey. After hearing detailed explanation on the objective of this investigation, 17 facilities expressed interest to participate in this survey. The researchers travelled to 17 agencies to conduct the face-to-face survey, and all the PHIs were invited to participate except those on business travel. Each participant was interviewed by interviewer following a structured questionnaire within $20 \mathrm{~min}$. All participants signed written informed consent. In total, 368 individuals completed the questionnaire.

The survey questionnaire was developed by the researchers, involving demographic variables, behavioural variables and cognitive variables. Demographic variables included gender, age, educational level, educational background and working experience: whether or not the PHIs were from epidemic prevention station. Behavioural variables derived from Gebbie and Merrill's model $^{14}$ were administered to participants if (1) they can identify and locate the agency's emergency response plan, (2) they can describe the agency's role in responding to emergencies that might arise and (3) they can describe one's own functions and roles in responding to emergencies that might arise. In addition, the participants were asked whether (1) they had ever experienced the public health emergencies, (2) they had ever been trained and (3) they had ever participated in drills in public health emergency-related areas. All the response option was 'Yes' or 'No'. Cognitive variables were selfassessment on general preparedness competency and specific preparedness competency derived from KSAs model $^{15}$. Responses were rated on an ordinal scale (1='very low', 2='low', 3='average', 4='high', 5='very high'). The specific competency measured three dimensions: knowledge (K), skill (S) and attitude (A). K1 for 'how knowledgeable they were with the condition of the administrative object ('not at all knowledgeable' to 'very knowledgeable')'; K2 for 'how knowledgeable they were with the legal powers associated with public health emergency ('not at all knowledgeable' to 'very knowledgeable')'; K3 for 'how knowledgeable they were about essential medical knowledge and theory ('not at all knowledgeable' to 'very knowledgeable')'; S1 for 'how proficiency they were to document appropriate information relative to the application of the law ('not at all proficiency' to 'very proficiency')'; S2 for" how proficiency they were to implement investigation and evidence collection ('not at all proficiency' to 'very proficiency')'; S3 for 'how proficiency they were to apply technique of rapid detection on-site ('not at all proficiency' to 'very proficiency')'; S4 for 'how proficiency they were to communicate with emergency response partners ('not at all 
proficiency' to 'very proficiency')' and A for 'how well they thought to maintain awareness of one's own activeness for job ('not at all ' to 'very well')'.

Pilot study with 20 PHIs working in nearby HIS agencies was conducted in October 2012, which focused on survey length, question clarity and whether respondents felt the survey to be neutral. Some minor amendments to wording were made in light of the responses. The main survey was then conducted from October to December, 2012.

Survey data were organised and analysed using SPSS statistical software V.19.0. Initial univariate descriptive statistics were obtained for the entire study. Pearson $\chi^{2}$ was used to examine demographic factors associated with self-rated preparedness competency. Those associations that were found to be significant $(p<0.05)$ were then analysed with multivariate logistic regressions following a step-wise modelling strategy. The self-rated general competency as dependant variable was dichotomised at the median. OR and their 95\% CIs were estimated to assess the relationship between the predictors and overall competency. The data of score on specific competency was analysed by one-way analysis of variance.

\section{In-depth interview}

Following the face-to-face survey, an in-depth interview was conducted onsite. The interviewees were purposively selected based on their roles and experience in public HIS in 17 agencies. Three senior researchers with extensive experience in qualitative research conducted all interviews in-person and one-on-one to ensure the feedback to be independent and confidential. Meanwhile, the researchers developed a semistructured interview protocol to ensure that all relevant topics were covered. Topics covered were: (1) to list all the important policy, institutional or other factors that have significant influence on the preparedness competency of PHIs, and how to divide them into different categories; (2) how the agencies either facilitated or impeded the preparedness activities, including interagency cooperation and (3) how the individual strengthen preparedness competency.

The interview data were categorised and analysed thematically by three researchers independently using triangulation method. The coding framework was developed inductively from the data. The initial coding used open coding (codes derived directly from the data) and theoretical coding. The initial codes were then refined to produce a smaller set of themes and a consensus was reached among researchers.

\section{RESULTS}

\section{Face-to-face survey}

The distribution of self-assessment on general preparedness competency

Of the 368 PHIs who participated in the face-to-face survey (see table 1), $44 \%$ and $38 \%$ of the respondents rated 'very high' and 'high' on their own competency contrasted with $12.8 \%$ on 'average', $3.8 \%$ on 'low' and $1.4 \%$ on 'very low'. Except for gender, there exist significant differences in sociodemographic characteristics on self-rated general competency. Those senior, better educated, without working experience in epidemic prevention station tended to have a relative higher self-assessment. Also, those respondents who have been trained, drilled or participated in emergency response activities tended to have clearer description on his/her own role as well as their agency's role in public health emergency response.

The reliability and validity of the structured questionnaires were tested by internal consistency (Cronbach's $\alpha=0.87$ ) and construct validity (related coefficient fluctuated between 0.36 and $0.77, \mathrm{p}<0.01$ ), which indicated that the evaluation instrument was of high quality and accredited.

\section{Factors associated with the general preparedness} competency by multivariate model

In multivariate analysis, the dependent variable of general preparedness competency was dichotomised according to the respondents' self-assessment level (those who rated themselves as good and very good enter in group 1 and those who rated themselves as average, low and very low enter in group 2; see table 2). Better knowledge and perception on their job description relating to public health emergencies response had the strongest association with increased general preparedness competency; those who clearly understood their job and role were 6.33 times (95\% CI 3.30 to 12.16) more likely to be competent than those who were ambiguous on their job responsibilities. The general competency score of those in 50-59 age group was 8.42 (95\% CI 1.67 to 42.56 ) times higher than those in 20-29 age group. Those having experience of public health emergency-related training was also associated with their increased competency by 2.22 times (95\% CI 1.31 to 3.74 ).

The multivariate model also showed that the history of previous working experience had a statistical significance relating to general preparedness competence of PHIs. Nearly half of the staff $(49.7 \%)$ who had undergone the agency reconstruction from epidemic prevention station were 0.41 times ( $95 \%$ CI 0.25 to 0.66 ) less likely to gain higher competency than their colleagues who were transferred from other sectors or were newly enrolled.

\section{Specific preparedness competency assessment based on KSAs model}

Significant difference among three dimensions in specific competency was found to be that 'attitude, A' had the highest average score $(3.92 \pm 0.66)$, compared with 'knowledge, K' $(3.61 \pm 0.66)$ and 'skills, S' $(3.53 \pm 0.80$; $\mathrm{p}<0.001$; see figure 1). The S3 'Application of technique of rapid on-site detection' $(3.11 \pm 0.86)$ and K3 'Being knowledgeable about essential medical knowledge and theory' $(3.51 \pm 0.67)$ were identified by PHIs as their weakness in skill and knowledge domain, respectively. 
Table 1 The distribution of self-assessment on general preparedness competency in this survey

\begin{tabular}{|c|c|c|c|c|c|c|c|}
\hline \multirow[b]{2}{*}{ Variable } & \multirow[b]{2}{*}{ N (\% of 368$)$} & \multicolumn{5}{|c|}{ Self-assessment on general preparedness competency } & \multirow[b]{2}{*}{ p Value } \\
\hline & & $\begin{array}{l}\text { Very low } \\
n \text { (\% of } 5)\end{array}$ & $\begin{array}{l}\text { Low } \\
n(\% \text { of } 14)\end{array}$ & $\begin{array}{l}\text { Average } \\
\text { n (\% of } 47)\end{array}$ & $\begin{array}{l}\text { High } \\
\text { n (\% of } 140)\end{array}$ & $\begin{array}{l}\text { Very high } \\
\mathrm{n}(\% \text { of } 162)\end{array}$ & \\
\hline \multicolumn{8}{|l|}{ Gender } \\
\hline Female & $161(43.8)$ & $3(60.0)$ & $8(57.1)$ & $24(51.1)$ & 60 (42.9) & $66(40.7)$ & 0.522 \\
\hline Male & 207 (56.2) & $2(40.0)$ & $6(42.9)$ & $23(48.9)$ & $80(57.1)$ & 96 (59.3) & \\
\hline \multicolumn{8}{|l|}{ Age } \\
\hline $20-29$ & $23(6.3)$ & 0 & $1(7.1)$ & $8(17.0)$ & $12(8.6)$ & $2(1.2)$ & 0.014 \\
\hline 30-39 & $125(34.0)$ & $2(40.0)$ & $3(21.4)$ & $20(42.6)$ & $50(35.7)$ & $50(30.9)$ & \\
\hline $40-49$ & $154(41.8)$ & $2(40.0)$ & $6(42.9)$ & $13(27.7)$ & 55 (39.3) & $78(48.1)$ & \\
\hline $50-59$ & 66 (17.9) & $1(20.0)$ & $4(28.6)$ & $6(12.8)$ & $23(16.4)$ & 32 (19.8) & \\
\hline \multicolumn{8}{|l|}{ Education } \\
\hline Senior high school & $57(15.5)$ & 0 & $4(28.6)$ & $11(23.9)$ & $22(15.7)$ & 20 (12.3) & \\
\hline Junior college & $142(38.6)$ & $2(40.0)$ & $7(50.0)$ & $13(28.3)$ & $68(48.6)$ & $52(32.1)$ & 0.007 \\
\hline University & $168(45.7)$ & $3(60.0)$ & $3(21.4)$ & $22(47.8)$ & $50(35.7)$ & $90(55.6)$ & \\
\hline \multicolumn{8}{|l|}{ Public health major } \\
\hline Yes & 188 (51.1) & $2(40.0)$ & $6(42.9)$ & $19(40.4)$ & $65(46.4)$ & $96(59.3)$ & 0.081 \\
\hline No & 180 (48.9) & $3(60.0)$ & $8(57.1)$ & $28(59.6)$ & $75(53.6)$ & $66(40.7)$ & \\
\hline \multicolumn{8}{|c|}{ Working experience (from epidemic prevention station) } \\
\hline Yes & $183(49.7)$ & $2(40.0)$ & $8(57.1)$ & $29(61.7)$ & $85(60.7)$ & $59(36.4)$ & 0.000 \\
\hline No & $185(50.3)$ & $3(60.0)$ & $6(42.9)$ & $18(38.3)$ & $55(39.3)$ & $103(63.6)$ & \\
\hline \multicolumn{8}{|c|}{ Emergency-related practices } \\
\hline \multicolumn{8}{|c|}{ With the experience in emergency response } \\
\hline Yes & $242(65.8)$ & $2(40.0)$ & $8(57.1)$ & $29(61.7)$ & $91(65.0)$ & $112(69.1)$ & 0.536 \\
\hline No & $126(34.2)$ & $3(60.0)$ & $6(42.9)$ & $18(38.3)$ & 49 (35.0) & 50 (30.9) & \\
\hline \multicolumn{8}{|c|}{ Trained in emergency response } \\
\hline Yes & $222(60.3)$ & $1(20.0)$ & $3(21.4)$ & $14(29.8)$ & $78(55.7)$ & $126(77.8)$ & 0.000 \\
\hline No & $146(39.7)$ & $4(80.0)$ & $11(78.6)$ & $33(70.2)$ & $62(44.3)$ & $36(22.2)$ & \\
\hline \multicolumn{8}{|c|}{ Participate in drill in emergency response } \\
\hline Yes & $171(46.5)$ & 0 & 0 & $12(25.5)$ & $62(44.3)$ & $97(59.9)$ & 0.000 \\
\hline No & $197(53.5)$ & $5(100.0)$ & $14(100.0)$ & $35(74.5)$ & $78(55.7)$ & $65(40.1)$ & \\
\hline \multicolumn{8}{|c|}{$\begin{array}{l}\text { Perception on emergency response } \\
\text { Identify and locate the agency emergency response plan }\end{array}$} \\
\hline Yes & $348(94.6)$ & $4(80.0)$ & $12(85.7)$ & $43(91.5)$ & $132(94.3)$ & 157 (96.9) & 0.146 \\
\hline No & $20(5.4)$ & $1(20.0)$ & $2(14.3)$ & $4(8.5)$ & $8(5.7)$ & $5(3.1)$ & \\
\hline \multicolumn{8}{|c|}{ Describe the agency's role in emergency response } \\
\hline Yes & $203(55.2)$ & $1(20.0)$ & $9(64.3)$ & $17(36.2)$ & $81(57.9)$ & $95(58.6)$ & 0.026 \\
\hline No & $165(44.8)$ & $4(80.0)$ & $5(35.7)$ & $30(63.8)$ & $59(42.1)$ & $67(41.4)$ & \\
\hline \multicolumn{8}{|c|}{ Describe one's own functional role in emergency response } \\
\hline Yes & $259(70.4)$ & $1(20.0)$ & $4(28.6)$ & $13(27.7)$ & $93(66.4)$ & $148(91.4)$ & 0.000 \\
\hline No & $109(29.6)$ & $4(80.0)$ & $10(71.4)$ & $34(72.3)$ & $47(33.6)$ & $14(8.6)$ & \\
\hline
\end{tabular}

\section{In-depth interview}

Of the 15 individuals who participated in the in-depth interview, 9 were PHIs who had taken part in previous face-to-face survey and 6 were agency's leaders. Half of the PHIs had working experience of epidemic prevention station and all the leaders had engaged in administrative work for more than 10 years. Three themes about preparedness competency of PHIs was categorised according to capacity assessment model developed by the $\mathrm{UNDP}^{18}$ (see figure 2) and a consensus had been reached. The inter-reliability ${ }^{19}$ was above $90 \%$.

Theme 1: The broader system, which includes the political, economic and physical environment factors, might have an original impact on the abilities of PHIs. In recent years, the Chinese government underwent frequent institution reshuffle on the administrative power over the supervision function on food hygiene, occupational hygiene and radiological protection, resulting in the inconsistent responsibilities among different agencies. Although there are relevant legislation and regulations for PHIs to act on, specific guidelines related to emergency response are still lacking.

Theme 2: In the institutional level, poor collaboration among agencies was found to be the hindrance for preparedness competency enhancement. Owing to the diversity characteristic of public health emergency and lack of special fund for preparedness, there exists overlapping function between health supervision agency and relevant agencies, resulting in the state that multiagencies executed law enforcement out of their own interests. 
Table 2 Factors associated with general preparedness competency of public health inspectors

\begin{tabular}{|c|c|c|c|c|}
\hline \multirow[b]{2}{*}{ Variables } & \multicolumn{2}{|l|}{ Full model* } & \multicolumn{2}{|c|}{ Parsimonious model† } \\
\hline & Coefficient & p Value & Coefficient & OR $(95 \% \mathrm{Cl})$ \\
\hline Age group (30-39) vs (20-29) & 1.963 & 0.016 & 1.940 & $6.96(1.44$ to 33.62$)$ \\
\hline Age group (40-49) vs (20-29) & 2.174 & 0.007 & 2.070 & $7.93(1.67$ to 37.73$)$ \\
\hline Age group (50-59) vs (20-29) & 2.434 & 0.004 & 2.131 & $8.42(1.67$ to 42.56$)$ \\
\hline Education (junior college) vs (senior high school) & 0.040 & 0.914 & - & - \\
\hline Education (University) vs (senior high school) & 0.702 & 0.077 & - & - \\
\hline $\begin{array}{l}\text { Have working experience of epidemic prevention station vs no } \\
\text { experience }\end{array}$ & -0.657 & 0.015 & -0.890 & $0.41(0.25$ to 0.66$)$ \\
\hline Have been trained in emergency response vs none & 0.714 & 0.032 & 0.795 & $2.22(1.31$ to 3.74$)$ \\
\hline Have participated in drill in emergency response vs none & 0.058 & 0.854 & - & - \\
\hline Describe the agency's role in emergency response vs not sure & 0.154 & 0.546 & - & - \\
\hline $\begin{array}{l}\text { Describe one's own functional role in emergency response vs not } \\
\text { sure }\end{array}$ & 1.881 & 0.000 & 1.846 & $6.33(3.30$ to 12.16$)$ \\
\hline
\end{tabular}

In addition, most of the agencies neglected the human resource management, which can detect their staff's competence deficiency.

Theme 3: At the individual level, half of the PHIs who were transferred from epidemic prevention stations

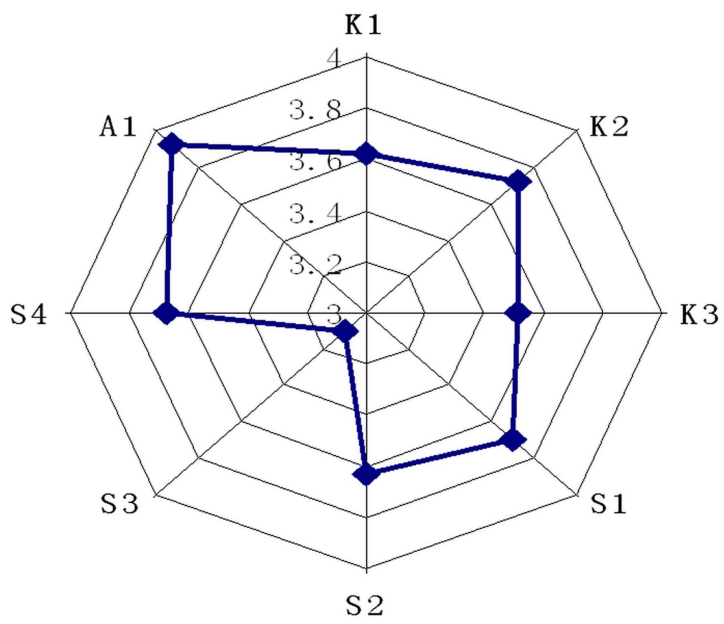

Figure 1 Self-rated score on specific preparedness competency of public health inspectors. A five-point Likert scale was adopted in which 1 was not at all competent and 5 was very competent. $\mathrm{K} 1$ for 'how knowledgeable they were with the condition of administrative object; K2 'how knowledgeable they were with the legal powers associated with public health emergency; K3 'how knowledgeable they were about essential medical knowledge and theory'; $\mathrm{S} 1$ 'how proficiency they were to document appropriate information relative to the application of the law'; S2 'how proficiency they were to implement investigation and evidence collection'; S3 'how proficiency they were to apply technique of rapid detection on-site'; S4 'how proficiency they were to communicate with emergency response partners'; A1 'how well they thought to maintain awareness of one's own activeness for job'. could not adapt well to their changing new jobs. Owing to lack of specific guideline and regular training and drill, many PHIs are confused with the emergencyrelated operational procedure and how to put relevant skills into practice.

\section{DISCUSSION}

This study focused on the preparedness competency of PHIs in China. The results showed that $44 \%$ and $38 \%$ of the respondents rated 'very high' and 'high' on their own competency while only $18 \%$ rated ordinary or below; due to the subjective nature of self-assessment, there may exist overestimation of their actual overall competency. $^{20-22}$ Therefore, it is necessary to decompose the general competency into specific domains to avoid systematic bias. The results showed that there existing an unsatisfactory performance in knowledge, skills among PHIs compared with their attitude score, the difference has statistical significance, especially in skills domain. As health law enforcement staff, PHIs need comprehensive competency to apply large-scale public health knowledge and skill to facilitate their law enforcement activities. ${ }^{10}$ Thus, improving being relevant knowledge and skill for PHIs should become a priority in the public health emergencies preparedness.

Further exploration on the factors influencing general preparedness competency of PHIs found that those junior, without better education, tended to be in the 'poor' level of self-assessment competency. Also, these respondents have seldom been trained or exercised in related emergency response and they were difficult to describe the agency's and his/her own role in emergency response. Meanwhile, PHIs who experienced institution reshuffle showed a low-level competency. One possible reason is that they could not be adapted to the changing responsibilities. More than $30 \%$ of PHIs who 
Figure 2 Factors associated with preparedness competency of public health inspectors from the qualitative analysis, which are grouped into three levels according to capacity assessment model developed by the UNDP: broader system, institutional level and individual level.

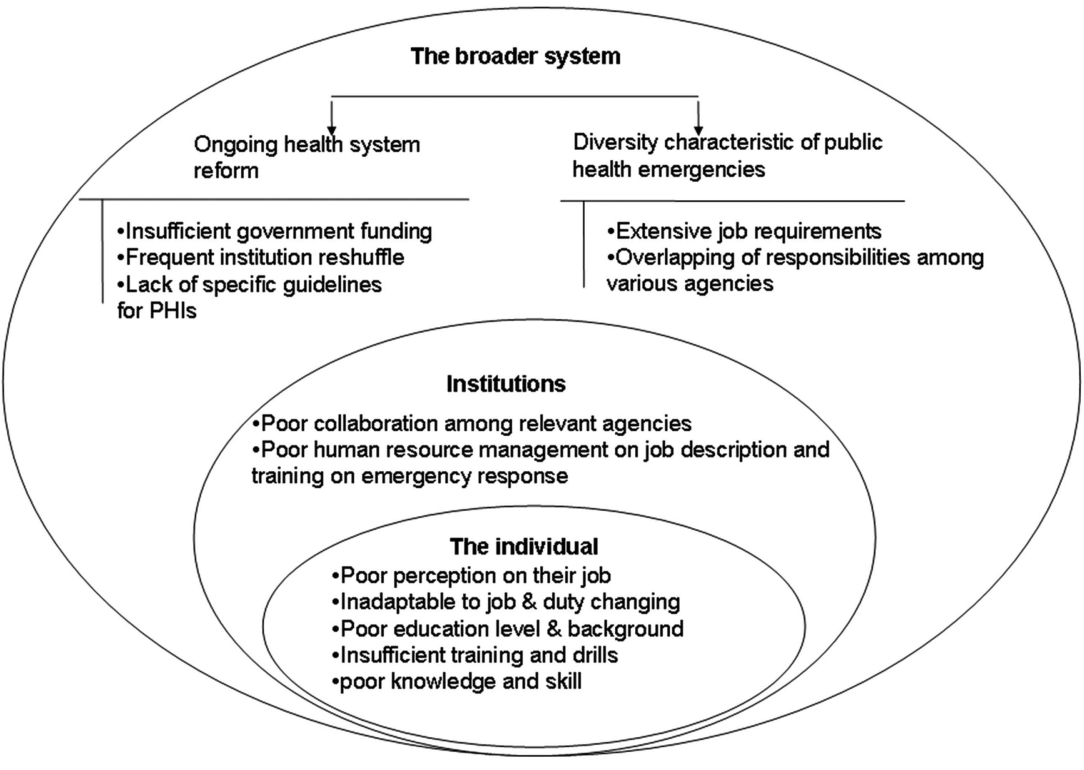

were transferred from the epidemic prevention station had confusion on their function and role. Most of those staff having public health education background found it difficult to switch to the present job of law enforcement, which not only led to the lower general preparedness competency, but also weak abilities in specific knowledge and skills domains.

Besides the major characteristic factors, awareness on one's specific function and role in emergency response was identified as the most important factor that have the strongest association with preparedness competency, which is consistent with previous studies. ${ }^{23-25}$ Kristine et $a l^{23}$ proposed that the first step towards emergency preparedness is the identification of who needs to know how to do what. Li et $a l \mathrm{~s}^{25}$ study also found that $91.8 \%$ of administrators of health supervision agency in China identified ambiguity of their function and role of PHIs in emergency response was the primary and key issue. However, reasons for the responsibilities ambiguity on PHIs are complex, which were also supported by the qualitative analysis.

The dominant reason might be due to the lack of specific guidelines related to emergency response at national level. Although the Chinese government has legislation and regulations on orientation and development for health supervision agencies, frequent institution reshuffle resulted in the overlapping work scope and ambiguity in job responsibilities among PHIs. At present, the responsibilities of PHIs only derived from National Public Health Emergency Response Plan and Specification of Health Emergency Management for National Health Department, which has not provided the detail job requirements for PHIs to respond to public health emergencies.

Another reason highlighted the poor collaboration between HIS and CDC. Separation from epidemic prevention station failed ${ }^{26} 27$ to achieve the reform goal as expected to improve the administrative law enforcement capacity of health system. According to the new legislation, the responsibilities of health surveillance and supervision were divided between CDC and HIS, respectively. Evidence has ${ }^{28}$ proven that only coordinated operation on surveillance and supervision can respond to public health threats more effectively. However, for seeking organisation's own interests, poor cooperation among different institutions was identified by all leaders interviewed as one of the most important factors that hindered the smooth implementation of their functional role and improvement of preparedness competency. The lowest score in skill of applying technique of rapid on-site detection in this study also partly explained this fact.

In addition, lack of effective human resource management at agency level disabled each organisation from identifying timely the weakness of their staff and to develop tailored training or drill programmes to enhance their overall competency in handling public health emergencies, which also influenced the awareness on responsibilities and competency enhancement of PHIs. Besides, the realities of basic personnel qualifications that were enrolled as PHIs are also not optimistic. The existence of staff who were little educated and lack of specialised training in grassroots also made it hard to adapt to the responsibilities changing. ${ }^{29}{ }^{30}$ Only through effective and continuous training and drilling programmes the preparedness competency of existing staff can be improved. ${ }^{31} 32$

There are a number of limitations existed in this study. Since we surveyed only 368 PHIs from 17 agencies in one province, which may not represent the overall situation of this target population, these findings could not be generalised to other geographic areas. Another issue that needs to be noted is that there may exist an overestimation of the PHIs general emergency preparedness competency level due to the adoption of selfassessment evaluation tool by this study. In order to get 
a better and more accurate estimation on the general competency of PHIs, there is a need to develop a more comprehensive evaluation tool together with objective and subjective indictors, so as to provide more accurate assessment on emergency preparedness competency of PHIs.

In conclusion, ambiguity in emergency responsibilities is the most important factor undermining the preparedness competency of PHIs. The findings of this study and cause analysis provided much needed evidence for China to better prepare its PHIs to meet the challenges brought by frequent public health emergencies.

Contributors QW, YH and NN designed and planned this study; LG and HS undertook the fieldwork and data collection; NN, ZK and MJ performed statistical analysis and wrote the first draft; QW and NN had full access to all the data in the study and take responsibility for the integrity of the data and the accuracy of the data analysis. QW and $\mathrm{YH}$ revised the article. NN, ZK and MJ contributed equally to this article.

Funding This study was funded by Scientific Research of Ministry of Health of China (grant no. 201002028), National High Technology Research and Development Program of China (grant no. 2006AA02Z460) and Natural Science Foundation of China (grant no. 71103052).

Competing interests None.

Ethics approval Ethical approval for this study was granted by the Institutional Research Board of Harbin Medical University in August 2012.

Provenance and peer review Not commissioned; externally peer reviewed.

Data sharing statement Data are available from the corresponding author upon request.

Open Access This is an Open Access article distributed in accordance with the Creative Commons Attribution Non Commercial (CC BY-NC 3.0) license, which permits others to distribute, remix, adapt, build upon this work noncommercially, and license their derivative works on different terms, provided the original work is properly cited and the use is non-commercial. See: http:// creativecommons.org/licenses/by-nc/3.0/

\section{REFERENCES}

1. Envionmental health officer from Wikipedia, the free encyclopedia. http://en.wikipedia.org/wiki/Environmental_health_officer

2. Wisner B, Adams J. Environmental health in emergencies and disasters: a practical guide. World Health Organization, 2002:51-7.

3. Savoia E, Rodday AM, Stoto MA. Public health emergency preparedness at the local level: results of a national survey. Health Serv Res 2009;44:1909-24.

4. World Health Organization. A safer future: global public health security in the 21st century. The world health report 2007. Switzerland, Geneva: World Health Organization, 2007.

5. Horsemeat scandal: S\&Ds criticize cuts in food safety inspections. http://www.socialistsanddemocrats.eu/gpes/public/detail.htm? id $=137927$ \&request_locale $=E N \&$ section $=N E R \&$ category $=N E W S$

6. China Daily. Sanlu to recall milk powder as baby dies. 2008. http:// www.chinadaily.com.cn/china/2008-09/12/content_7020499.htm (accessed Feb 2009).

7. Cui X, He X, Zhang WH, et al. The history of the health supervision system in China. Chin J Health Inspection 2007;14:157-60.
8. Ministry of health in China. The notice with opinion on reform of health supervision system. http://www.moh.gov.cn/wsb/pzcjd/ 200804/25191.shtml

9. Lv J, Li LM. The comparison on function between modern public health and CDC\&HIS in China. Chin J Public Health Manag 2006;22:365-8.

10. Wang XM. Discussion on capacity building of health supervision system. Chin Rural Health Serv Adm 2008;28:631-3.

11. Cao JS, Song WZ, Zhao TG. Analysis on the current situation of public health inspectors. Chin J Public Health Manag 2002;18:182-5.

12. Chen WJ, Huang J, Mai GY, et al. Discussion on emergency preparedness competency of public health inspectors. Chin $\mathrm{J}$ Health Inspection 2010;17:377-9.

13. Zhou HW. How to strengthen the capacity of health supervision in China. Chin J Public Health Manag 2007;23:148-9.

14. Gebbie K, Merrill J. Public health worker competencies for emergency response. J Public Health Manag Pract 2002;8:73-81.

15. Association of Schools of Public Health and CDC of America. Knowledge, skills and attitudes (KSAs) for the public health preparedness and response core competency model. 2012. http:// www.asph.org/userfiles/KSA.pdf

16. Bureau of health in Heilongjiang. Health statistics yearbook in Heilongjiang province. Heilongjiang: Provincial Press, 2011.

17. Bureau of Statistics in Heilongjiang. Statistics yearbook in Heilongjiang province. Heilongjiang: Provincial Press, 2011.

18. UNDP. Capacity assessment and development in a systems and strategic management context. 1998.http://mirror.undp.org/magnet/ Docs/cap/CAPTECH3.htm

19. Armstrong D, Gosling A, Weinman J, et al. The place of inter-rater reliability in qualitative research: an empirical study. Sociology 1997;31:597-606

20. Kerby DS, Brand MW, Johnson DL, et al. Self-assessment in the measurement of public health workforce preparedness for bioterrorism or other public health disasters. Public Health Rep 2005;120:186-91.

21. Kruger J, Dunning D. Unskilled and unaware of it: how difficulties in recognizing one's own incompetence lead to inflated self-assessments. J Pers Soc Psychol 1999;77:1121-34.

22. Canyon DV. An assessment of bioterrorism competencies among health practitioners in Australia. Emerg Health Threats J 2009;2:e7. http://www.eht-journal.net/index.php/ehtj/article/view/7087/7978

23. Gebbie KM, Qureshi K. Emergency and disaster preparedness: core competencies for nurses: what every nurse should but may not know. AJN 2002;46-51.

24. Balicer RD, Omer SB, Barnett DJ, et al. Local public health workers' perceptions toward responding to an influenza pandemic. BMC Public Health 2006;6:99.http://www.biomedcentral.com/1471-2458/ $6 / 99$

25. Li CY, Jiang HL, Chen R, et al. The most important issue of health supervision system: absence of function. Chin J Health Inspection 2007:14:317-18.

26. Hou FZ. Investigation and analysis on the health supervision system in China. Chin J Health Inspection 2006;13:410-13.

27. Xing GT, Meng FL. Several critical issues about health inspection. Chin J Health Inspection 1998;5:82-6.

28. Zhao TG. Discussion on the health supervision system reform and development of system building. China Health Law 2009;17:4-12.

29. Jia HL, Xu Y, Chen G, et al. Research on the allocation of human resources in health inspection agencies. Chin $J$ Health Inspection 2008;15:166-70.

30. Chen G, Cui X, Sun XX, et al. Research on the staff of Health Inspection Agency of China. Chin J Health Inspection 2006;13:410-13.

31. Sidika TY. Public health and natural disasters: disaster preparedness and response in health systems. J Public Health 2006;317-24.

32. Gebbie KM. Role of exercises and drills in the evaluation of public health in emergency response. Prehosp Disaster Med 2006;21:173-82. 